
for Mechanical Engineering

\title{
Prediction of forming characteristics of titanium alloy self- locking nuts
}

\begin{tabular}{|r|l|}
\hline Journal: & Transactions of the Canadian Society for Mechanical Engineering \\
\hline Manuscript ID & TCSME-2020-0201.R1 \\
\hline Manuscript Type: & Article \\
\hline Date Submitted by the & 18 -Jul-2021 \\
\hline $\begin{array}{r}\text { Complete List of Authors: } \\
\text { Kang, Xinsheng; Yantai University, School of Electromechanical and } \\
\text { Automotive Engineering } \\
\text { Liu, Kuanyu; Yantai University, School of Electromechanical and } \\
\text { Automotive Engineering, Yantai University } \\
\text { Li, Zhou; Yantai University, School of Electromechanical and Automotive } \\
\text { Engineering } \\
\text { Zhu, Weijin; Shenyang SIASUN Robot \& Automation Co., LTD. }\end{array}$ \\
\hline $\begin{array}{r}\text { Keywords: } \\
\text { consideration in a Special } \\
\text { Issue? : }\end{array}$ & $\begin{array}{l}\text { Titanium alloy, Self-locking nut, Upset forging formation, Finite element } \\
\text { method }\end{array}$ \\
\hline invited manuscript for &
\end{tabular}

\section{SCHOLARONE \\ Manuscripts}




\section{Prediction of forming characteristics of titanium alloy self-locking nuts}

Xin Sheng Yang ${ }^{\mathrm{a}}$, Kuan Yu Liu ${ }^{\mathrm{a}}$, Li Zhou ${ }^{\mathrm{a}}$, and Wei Jin Zhu ${ }^{\mathrm{b}}$

a School of Electromechanical and Automotive Engineering, Yantai University, Yantai 264005, P.R. China.

b Shenyang SIASUN Robot \& Automation Co., LTD. Shenyang 110169, P.R. China.

Corresponding author: Li Zhou (email: lizhou@ytu.edu.cn). 


\begin{abstract}
Titanium alloy is an important class of aerospace material due to its high specific strength, excellent anti-corrosion and anti-oxidation. In this paper, a three-dimensional thermo-mechanical coupled simulation was carried out to predict the formation characteristics of TC4 titanium alloy selflocking nut during the upset forging process. The stability of the upset forging was analyzed, and the influences of initial temperature and deformation velocity on the formation quality were investigated. The results show that if length-diameter ratio of the sample less than 3.27, the upset forging formation tends to be stable, and here, the length-diameter ratio of 2.89 was selected. Additionally, the forming quality of TC4 self-locking nut improves with the increase of initial temperature and decreases with the increase of the velocity of the upper die. The analysis results can provide a theoretical guidance for the upset forging formation of TC4 titanium alloy nuts.
\end{abstract}

Keywords: Titanium alloy, Self-locking nut, Upset forging formation, Finite element method. 


\section{Introduction}

Titanium alloy has the advantages of light weight, high specific strength and corrosion resistance. Therefore, it is widely used in important industrial sectors such as aviation, aerospace, shipbuilding (Mohanraj and Elangovan 2020; Yeganefar and Niknam et al. 2020; Kazuhiro et al. 2010). For aircraft, the lighter the weight, the lower the flight cost, so titanium alloy is often used as aircraft bearing components. In addition, titanium alloy fastener, for example bolts, nuts and screws can provide upgraded performance due to the benefit of strong, lightweight, and corrosion resistant.

At present, there are two main processing methods for titanium alloy nuts: turn-milling and upset forging (Wang et al. 2015). Compared with turning and milling, upsetting process of titanium alloy nut has many advantages (Liu et al. 2020), such as good quality consistency, high production efficiency and high material utilization ratio, and so on. During the upset forging forming, the material is in a threedimension compression state, which will change the microstructure, refine the grain and improve mechanical properties (Wang, L. D. et al. 2015; Hsia and Chou 2016). TC4 is a typical two-phase $(\alpha+\beta)$ titanium alloy, and alpha is close to the hexagonal crystal. After cold working, TC4 shows poor performance (Zhang et al. 2021). Generally, after heating to high temperature (below the phase transition point), the primary $\alpha$ phase of TC4 decreases, and the strip $\beta$ t (the $\beta$ phase transformed by $\alpha$ ) increases, then, the plasticity improves and the deformation resistance decreases greatly (Wang et al. 2020; Paul M et al. 2019; Cheng et al. 2020; Luo et al. 2020). Therefore, about $80 \%$ of titanium and titanium alloy components are manufactured by hot forging operations (Zhang et al. 2013). According to previous studies, as an important forging factor, initial temperature influences forming quality significantly. Seetharam et al. (2017) investigated the influence of temperature on the workability behavior, stresses and hardness of sintered Al-4\%B4C at strain rate of $0.1 \mathrm{~s}^{-1}$ during upsetting. Shi et al. (2010) researched the effects of forging temperature on mechanical property and microstructure of TC4-DT titanium. The results show that when the upsetting temperature is below the transformation point, the tensile strength is positively correlated with the temperature, and when the upsetting temperature is above the transformation point, the tensile strength is negatively correlated with the temperature. Werner, W. and Werner, S. (2019) observed the microstructure of ODS silver alloys and the development of texture in hot-extrusion process. Artem et al. (2020) established a model to predict the mechanical properties of TC4 based on microstructure evolution simulation during thermomechanical processing. Jiang et al. 
(2020) studied the hot tensile features, fracture mechanisms and microstructure evolution of a Ti-6Al$4 \mathrm{~V}$ alloy with initial coarse equiaxed phases. Up to now, most studies focus on the microstructure and mechanical properties evolutions of TC4 under different temperatures, few reports have focus on the TC4 components hot forging formation. TC4 titanium alloy self-locking nuts have the complex surface, and an accurate prediction of the initial temperature effect on formation quality is of great important for improving the formation quality and mechanical properties of TC4 nuts. Finite element (FE) modeling can reduce the burden of extensive experimental trials in understanding the formation mechanism and optimize the forming process.

In this paper, the hot upsetting process of TC4 self-locking nuts was analyzed using ABAQUS software. The temperature distribution and strain distribution during the hot upsetting process were investigated. Moreover, the influences of initial temperature and velocity of the upper die on the formation quality of TC4 nuts were compared.

\section{Finite element analysis}

\subsection{Creation of geometric model}

Three parts are created and assembled in ABAQUS, and their mutual positions are determined. As shown in Fig. 1, the upper die is a square plane, the bottom die is obtained by cutting cuboid with nut according to boolean operation in Abaqus/CAE, and they are all defined as rigid bodies. The billet is a cylindrical deformable body. In addition, it should be noted that the volume of the cylindrical billet must be equal to the volume of the self-locking nut (Shen et al. 2014).

Fig. 1. Finite element model of upset forging formation. (a) three-dimensional model. (b) cross section.

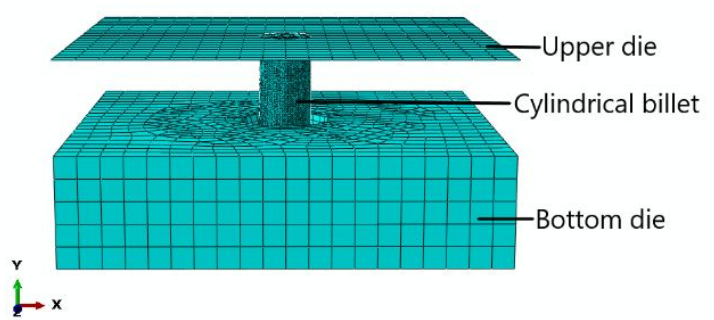

(a)

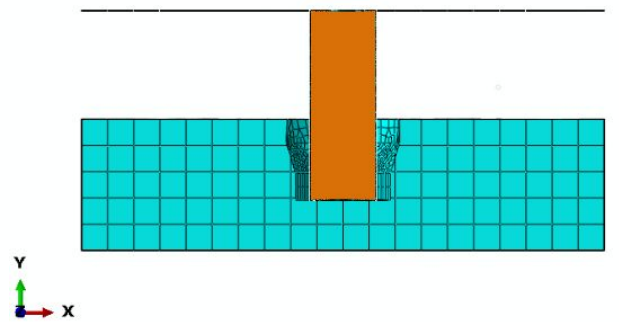

(b)

\subsection{Definition of material properties}

To simulate the upset forging formation of TC4 nuts, the influence of temperature on the whole process should be considered. The material properties include elasticity, plasticity and the related thermophysical parameters. The density of TC4 titanium alloy is $4.51 \times 10^{3} \mathrm{~kg} / \mathrm{m}^{3}$. The elastic modulus and thermophysical parameters can be known from The Aeronautical Materials Handbook, and it can be seen that the relationship between temperature and parameters is almost linear, as shown in Fig. 2 (Editorial board of China Aviation Materials Handbook. 2002). Moreover, Yang et al. (2016) have verified the linear relationship between temperature and elastic modulus through experiment. Therefore, the required material parameters are calculated by fitting method, and the linear fitting equation can be expressed as:

$$
Y\left(E, c, \lambda, \alpha_{1}\right)=K \cdot T+b
$$

where, $E$ is elastic modulus, $c$ is specific heat, $\lambda$ is thermal conductivity, $\alpha_{1}$ is expansion coefficient, and $T$ is temperature. $K$ and $b$ are the slope and intercept of the fitting line respectively. The fitting equations are shown in Table 1, and based on this, required material parameters are gained as shown in red points (Fig. 2).

Table 1. Specific fitting equations.

\begin{tabular}{cc}
\hline Required parameters under different temperature & Fitting equation \\
\hline$E(\mathrm{GPa})$ & $E=-7.63 \times 10^{-2} T+110.326$
\end{tabular}




$$
\begin{array}{cc}
c(\mathrm{~J} / \mathrm{g} \cdot \mathrm{K}) & c=2.31 \times 10^{-4} T+0.6 \\
\lambda(\mathrm{W} / \mathrm{m} \cdot \mathrm{K}) & \lambda=1.08 \times 10^{-2} T+6.32 \\
\alpha_{1}\left(\mathrm{x} 10^{-6} \mathrm{~K}^{-1}\right) & \alpha_{1}=1.68 \times 10^{-3} T+9.068
\end{array}
$$

Fig. 2. Variation of material constant with temperature. (a) elastic modulus. (b) specific heat. (c) thermal conductivity. (d) coefficient of thermal expansion.

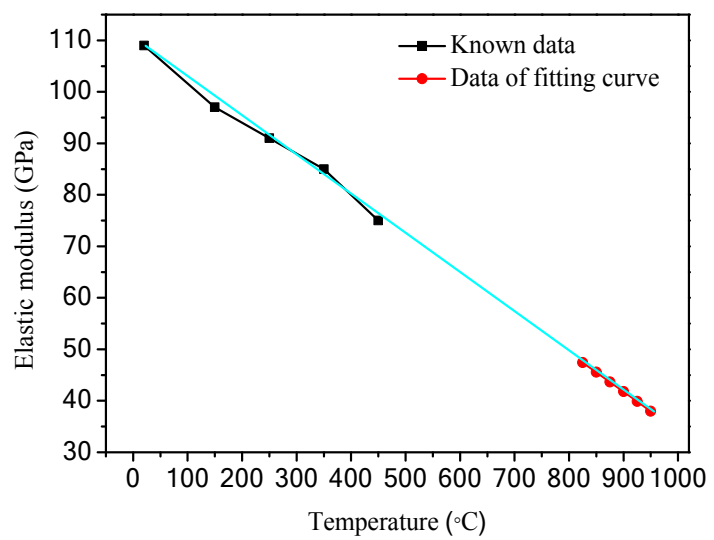

(a)

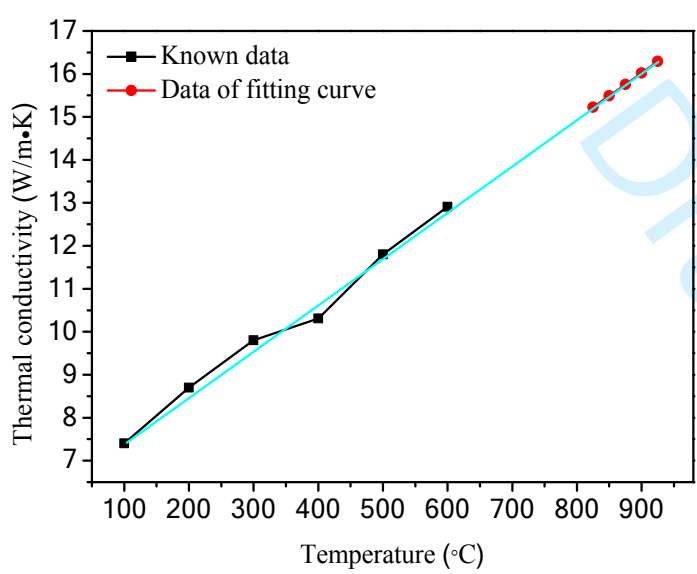

(c)

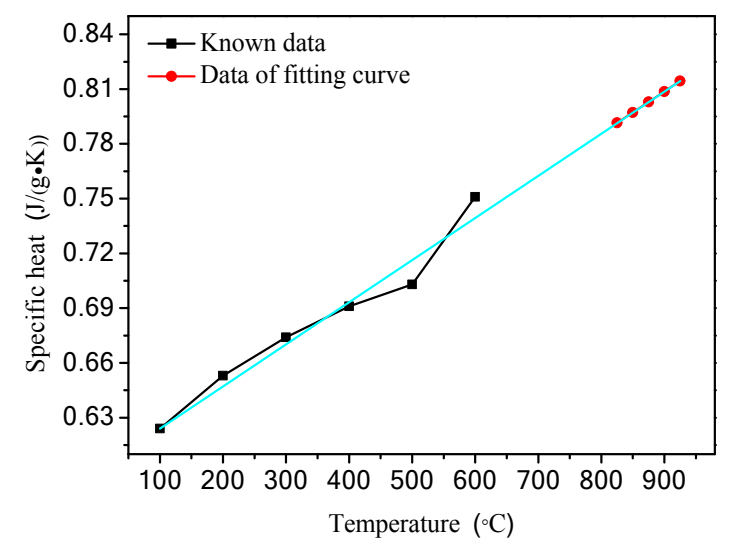

(b)

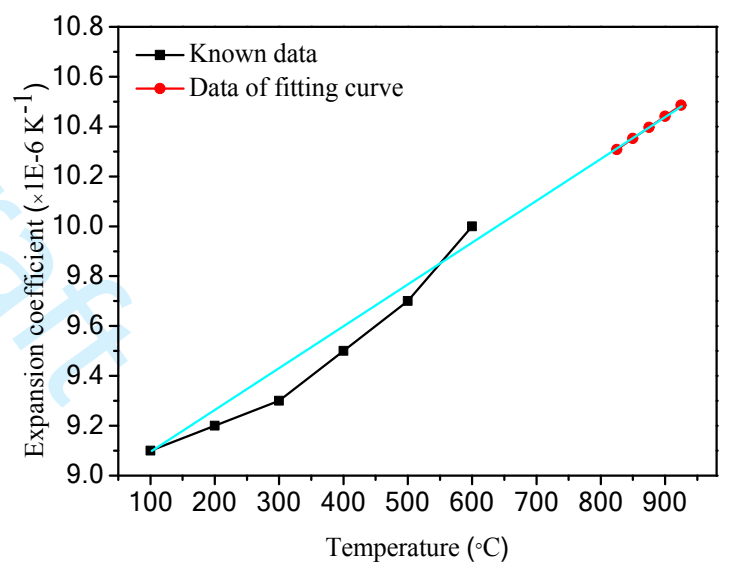

(d)

It is well known that Arrhenius equation is widely used to describe the dependence of flow stress on the temperature and strain rate in hot deformation process (Cai et al. 2011; Abbasi-Bani et al. 2014). Fig. 3 shows the stress-strain curves of TC4 titanium alloy at various strain rates and temperatures (Zhao et al. 2015), which can be used to determine the Arrhenius-type constitutive equation: (Cai et al. 2011; Huang et al. 2019):

$$
\begin{gathered}
\dot{\varepsilon}=\mathrm{A}_{1} \sigma^{\mathrm{n}_{1}} \\
\dot{\varepsilon}=A_{2} \exp (\sigma \beta) \\
\dot{\varepsilon}=A[\sin (\alpha \sigma)]^{n} \exp \left(-\frac{Q}{R T}\right) \\
\mathrm{Z}=\dot{\varepsilon} \exp \left(\frac{Q}{R T}\right)=A[\sin (\alpha \sigma)]^{n}
\end{gathered}
$$

where $R$ is the universal gas constant $\left(8.3145 \mathrm{~J} \cdot \mathrm{mol}^{-1} \cdot \mathrm{K}^{-1}\right), Q$ is the activation energy, $\dot{\varepsilon}$ is the strain rate, $\alpha, A \quad n_{1}$ and $n$ are the materials constants, and $\alpha=\beta / n_{1}, Z$ is called ZenerHollomon parameter. Taking the logarithm of both sides of Eqs. (2) and (3), the following equations can be obtained:

$$
\begin{gathered}
\ln \dot{\varepsilon}=n_{1} \ln \sigma+\ln A_{1} \\
\ln \dot{\varepsilon}=\beta \sigma+\ln A_{2}
\end{gathered}
$$


Obviously, the relationships of $\ln \dot{\varepsilon}-\ln \sigma$ and $\ln \dot{\varepsilon}-\sigma$ at different temperatures are almost linear, as shown in Fig. 4a (Zhao et al. 2015) and Fig. 4b. And the slopes of the lines represent $n_{1}$ and $\beta$, so the values of $n_{1}$ and $\beta$ were calculated to be 2.74 and $0.0533 \mathrm{MPa}^{-1}$, and this gives the value of $\alpha=\beta / n_{1}=0.01945 \mathrm{MPa}^{-1}$. In the same way, taking the logarithm of both sides of the Eq. (4). For a particular temperature, the value of $n$ can be obtained from the slope of the linear fitting lines in the $\ln [$ $\sinh (\alpha \sigma)]-\ln \dot{\varepsilon}$ (Fig. 4c). For a given strain rate, the value of activation energy $Q$ can be obtained from the slope of the linear fitting lines in the $\ln [\sinh (\alpha \sigma)]-1000 / T$ (Fig. 4d). Finally, the values of $n$ and $Q$ were calculated to be 1.8933 and $211.2125 \mathrm{KJ} \cdot \mathrm{mol}^{-1}$. Moreover, taking the logarithm of both sides of Eq. (5), the values of $A$ are calculated to be about $e^{-4.2157}$. Finally, the constitutive equation that relates the flow stress and $Z$ parameter can be written as:

$$
\sigma=\frac{1}{\alpha} \ln \left\{\left(\frac{Z}{A}\right)^{1 / n}+\left[\left(\frac{Z}{A}\right)^{2 / n}+1\right]^{1 / 2}\right\}
$$

Eq. (8) is used to build the constitutive equations of TC4 titanium alloy at strain rates from 0.001 to $0.1 \mathrm{~s}^{-1}$ and temperatures from 825 to $925^{\circ} \mathrm{C}$, which is coded in FORTRAN in the form of a user material (VUMAT).

Fig. 3. Actual stress-strain curves of TC4 titanium alloy at (a) $0.1 s^{-1}$. (b) $0.01 s^{-1}$. (c) $0.001 s^{-1}$ at different temperatures and (d) $900{ }^{\circ} \mathrm{C}$ at different strain rates.

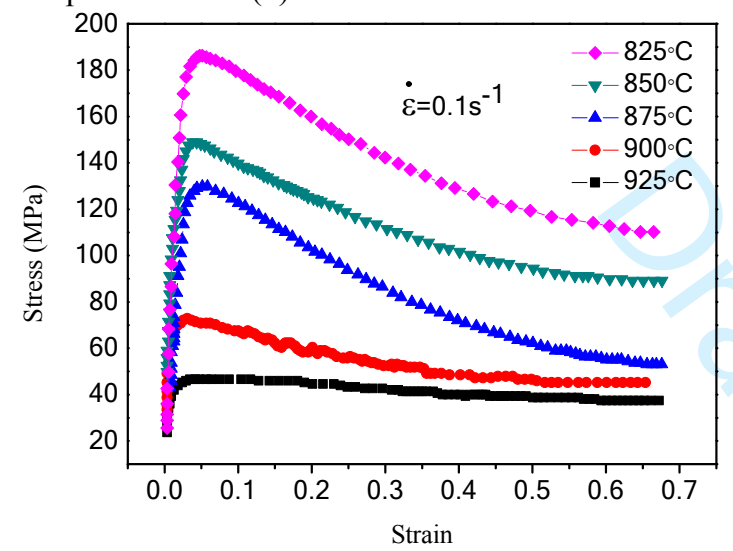

(a)

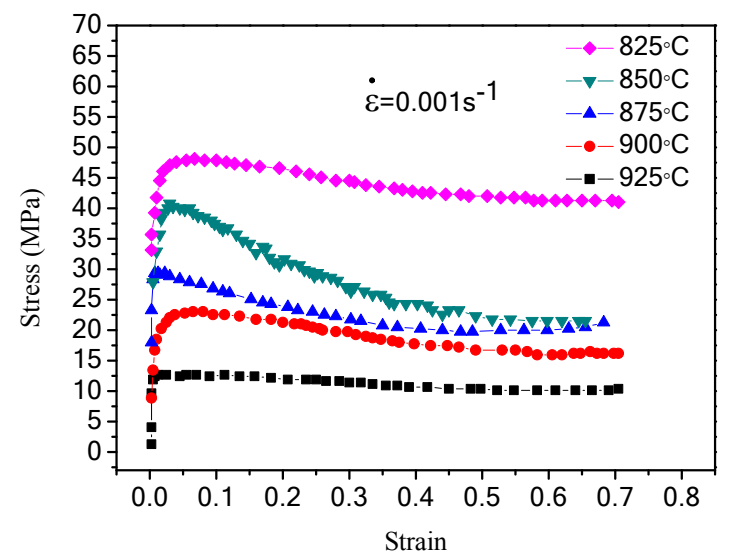

(c)

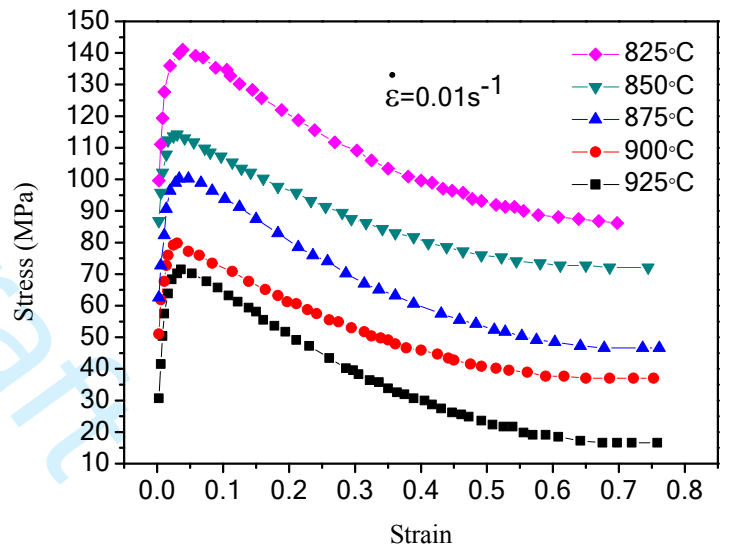

(b)

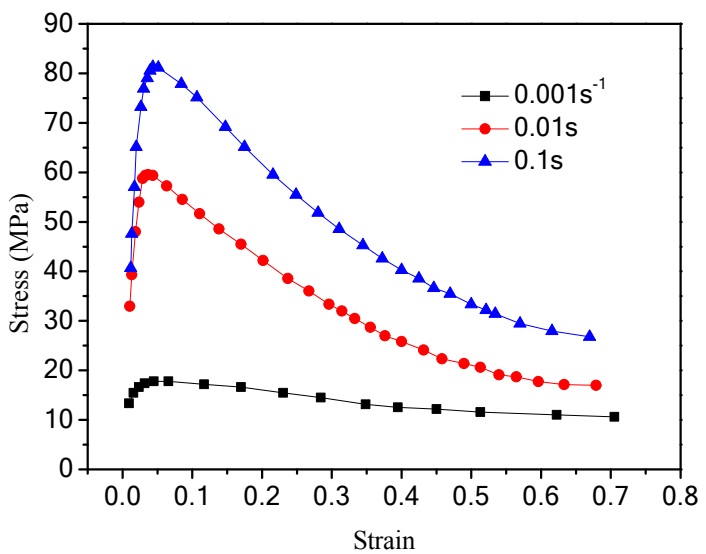

(d)

Fig. 4. Evaluation of (a) $n_{1}$ by plotting $\ln \dot{\varepsilon}-\ln \sigma$, (b) $\beta$ by plotting $\ln \dot{\varepsilon}-\sigma$, (c) $n$ by plotting $\ln [\sinh (\alpha \sigma$ )] $-\ln \dot{\varepsilon}$ and (d) $Q$ by plotting $\ln [\sinh (\alpha \sigma)]-1000 / T$. 


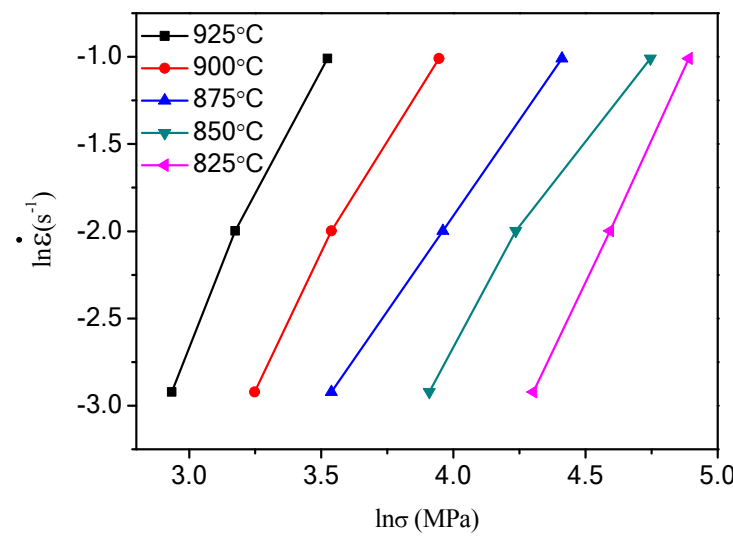

(a)

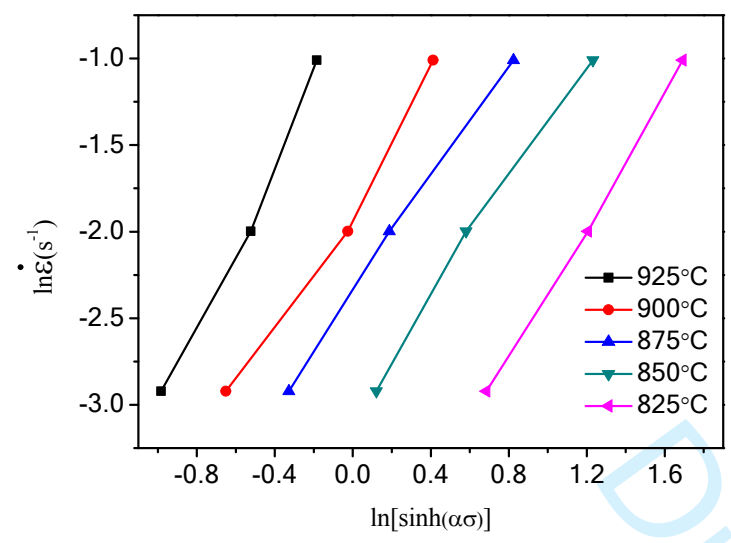

(c)

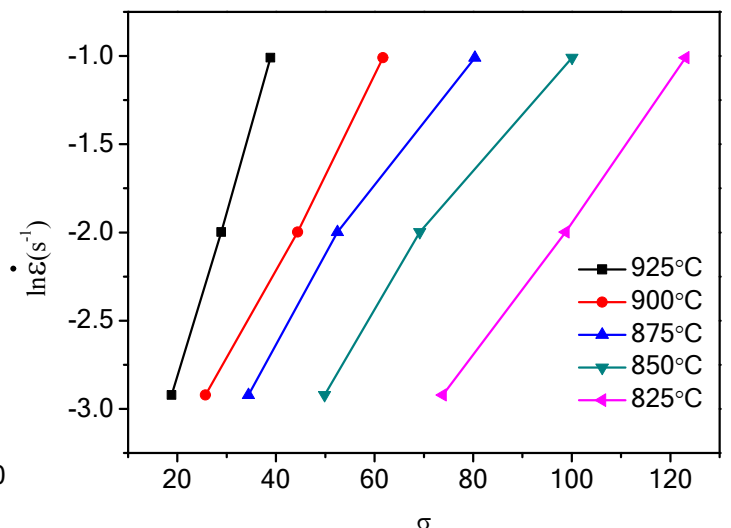

(b)

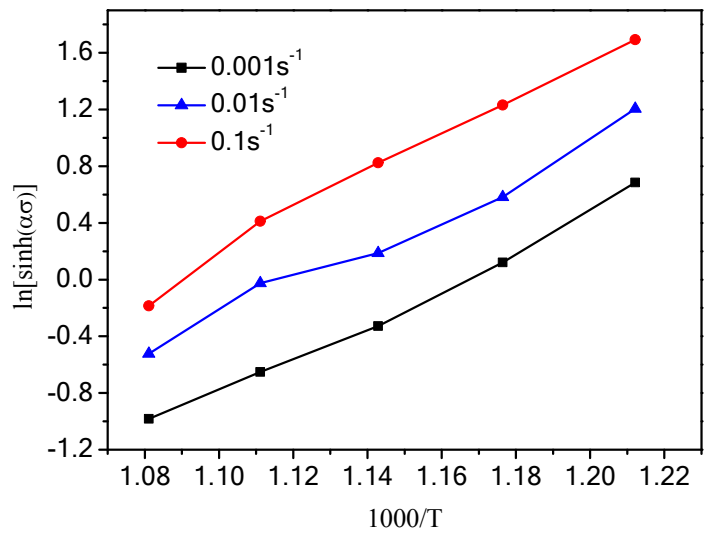

(d)

\subsection{Determination of the upsetting temperature}

Fig. 5. Assembly of TC4 self-locking nut upset forging formation.

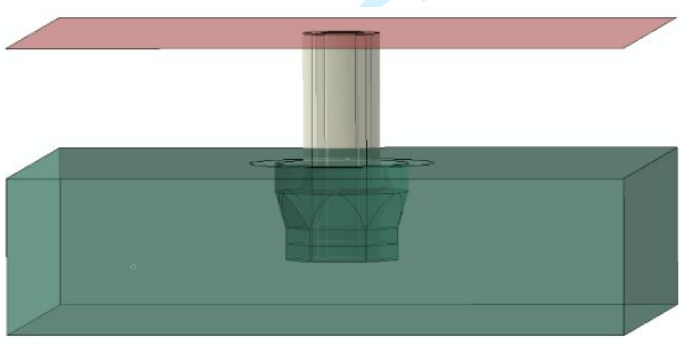

$\stackrel{\leftrightarrow}{\longrightarrow}$

As shown in Fig. 5, the shape and structure of TC4 nuts are complex, which increases the difficulty of hot upsetting. If one-time hot upsetting is used, the deformation degree should be lower than the allowable degree of deformation at the upsetting temperature (Wang, L. D. et al. 2015). The allowable degree of deformation can be calculated from the Eq. (9):

(9)

$$
\varepsilon=\left(A_{1}-A_{0}\right) / A_{1}
$$

where, $\varepsilon$ is the allowable degree of deformation, $A_{1}$ is the area the bottom circle of the nut after upsetting, and $A_{0}$ is the area of contact between the upper die and the cylindrical billet.

In this model, $A_{1}=58.90 \mathrm{~mm}^{2}, A_{0}=19.63 \mathrm{~mm}^{2}$, substituting them into Eq. (9), in that way, the deformation degree of the upset forming of the analysis is $66.67 \%$. Obviously, as shown in Fig. 6, the deformation degree $(66.67 \%)$ is lower than the allowable deformation degree during $825^{\circ} \mathrm{C} \sim 975^{\circ} \mathrm{C}$. In addition, the deformation temperature has significant effects on the microstructure evolution (Jiang et al. 2021; Xiao et al. 2020). Too high temperature (over the $\beta$-transus temperature, about $975^{\circ} \mathrm{C}$ ) will cause 
the growth of $\beta$ grains, which will result in the increase of average grain size (Jiang et al. 2020; Liu et al. 2018), at this time, the mechanical properties decrease. To meet the requirement of the allowable deformation degree and prevent heat generated by fierce deformation from causing the temperature to cross the phase transition point $\left(975^{\circ} \mathrm{C}\right)$, therefore, we choose $825^{\circ} \mathrm{C} \sim 925^{\circ} \mathrm{C}$ as the range of initial temperature for this analysis.

Fig. 6. Allowable deformation degree at different temperatures.

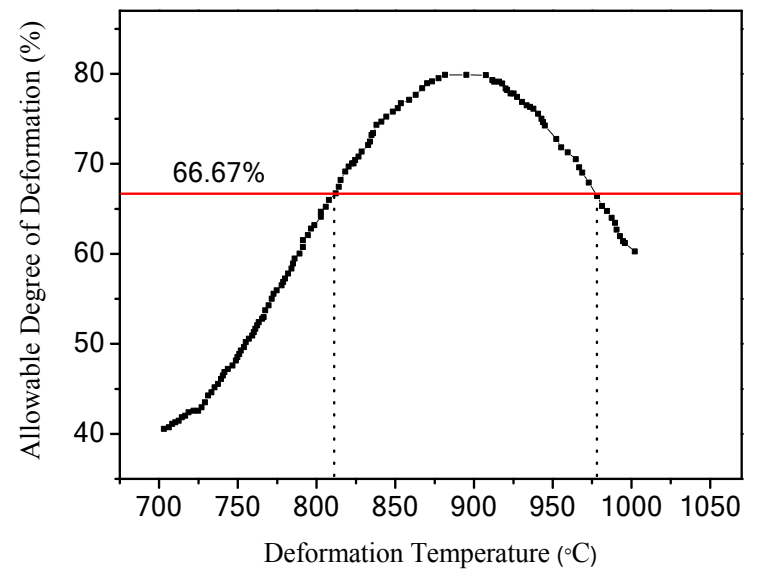

\subsection{Step and boundary condition}

ABAQUS software will automatically create an initial analysis step, and constraints can be added to limit the freedom of the part in this step but cannot set specific velocity and displacement. Therefore, it is necessary to create a new temperature-displacement coupled explicit analysis step and add the following boundary conditions: a) fix the bottom die; b) set the velocity of the upper die; c) set the predefined temperature field to $825^{\circ} \mathrm{C} \sim 925^{\circ} \mathrm{C}$ (cylindrical billet) and $20^{\circ} \mathrm{C}$ (two dies).

\subsection{Definition of contact}

As shown in Fig. 7, the contact is divided into two parts: a) the contact between the bottom surface of the upper die and the cylindrical billet; b) the contact between the cavity of the bottom die and the cylindrical billet, and the coefficient of friction is 0.1 (Wang, D. G et al. 2008). During the contact process, there are three ways of heat transfer: heat conduction, heat convection, and heat radiation. And this analysis ignores the influence of thermal radiation, only considers the heat conduction in the process of contact, and defines the heat dissipation of the surface with a default film coefficient of 0.1 and sink temperature of $20^{\circ} \mathrm{C}$.

Fig. 7. Contact pairs. (a)upper die and cylindrical billet. (b) bottom die and cylindrical billet

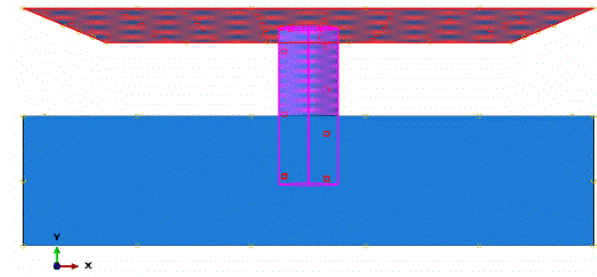

(a)

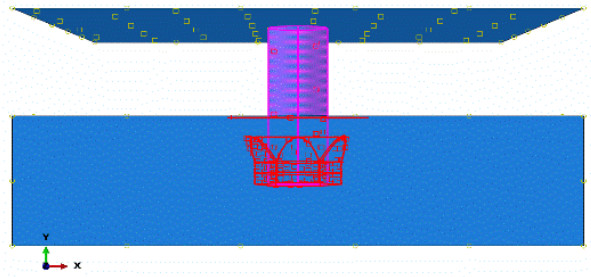

(b)

\subsection{Mesh generation}

The upper die and bottom die are meshed by 4-node thermally coupled doubly curved thin shell elements (S4RT), and the cylindrical billet is meshed by 10-node modified thermally coupled secondorder tetrahedral elements (C3D10MT). Moreover, the selection of mesh size should be based on the principle of ensuring solution accuracy and minimizing solution time (Maarefdousta and Hosseyni 2011). 
The upper and bottom dies are defined as rigid bodies, so we only consider the influence of the mesh size of the billet on the von Mises stress and analysis time. Thus, different global seeds are set on the cylindrical billet for grouping analysis, as shown in Table 2. In addition, the relationship among the mesh size, the von Mises stress and the analysis time is shown in Fig. 8, the von Mises stress and analysis time increase with the decrease of mesh size, and when the mesh size is about $0.15 \mathrm{~mm}$, the stress value tends to be stable. Therefore, the mesh size of the billet is taken as $0.15 \mathrm{~mm}$, at this point, the model of the billet consists of 238,841 quadratic tetrahedral elements.

Table 2. Grouping analysis.

\begin{tabular}{cccc}
\hline Mesh size/mm & Number of elements & von Mises/MPa & Analysis time/min \\
\hline 0.8 & 6150 & 64.58 & 12 \\
0.7 & 8105 & 74.1 & 15 \\
0.6 & 10051 & 80.86 & 20 \\
0.5 & 15658 & 85.42 & 31 \\
0.4 & 32068 & 90.13 & 48 \\
0.3 & 70569 & 91.32 & 75 \\
0.2 & 130309 & 91.85 & 105 \\
0.15 & 238841 & 91.18 & 151 \\
\hline
\end{tabular}

Fig. 8. Relationship between mesh size, von Mises stress and analysis time.

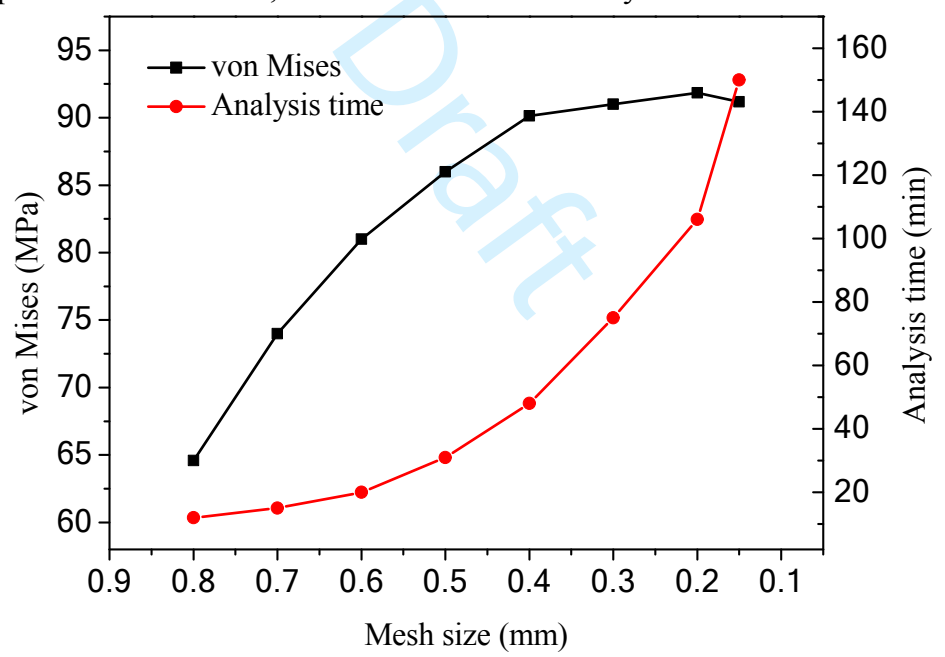

\section{Result and analysis}

\subsection{Forming stability}

During the hot upsetting process, the length and diameter of the cylindrical billet will seriously affect the stability of the upsetting process (Feng et al. 2018; Kukhar et al. 2021). If the distance between upper die and bottom die is too long, the cylindrical billet will be distorted due to poor stability during upsetting, which will seriously affect the forming process. Therefore, the length-diameter ratio is used as a variable for simulation, as shown in Table 3. And the hot upsetting shape with different length-diameter ratio can be seen from the Fig. 9, it shows that the larger the length-diameter ratio of the billet is, the easier it is to distort. With the length-diameter ratio decreases, the distortion disappears gradually, and when the length-diameter ratio is less than 3.27, the upset forging formation tends to be stable. Consequently, the cylindrical billet with the length-diameter ratio of 2.89 was selected for this analysis.

Table 3. Grouped data.

\begin{tabular}{ccc}
\hline Length $(\mathrm{L}), \mathrm{mm}$ & Diameter $(\mathrm{D}), \mathrm{mm}$ & The length-diameter ratio, L:D \\
\hline 27.91 & 3.6 & 7.75
\end{tabular}




\begin{tabular}{lcl}
22.60 & 4 & 5.65 \\
18.68 & 4.4 & 4.25 \\
15.70 & 4.8 & 3.27 \\
14.47 & 5 & 2.89 \\
\hline
\end{tabular}

Fig. 9. Hot upsetting shape with different length-diameter ratio L:D of (a) 7.75. (b) 5.65. (c) 4.25. (d) 3.27. and (e) 2.89 .

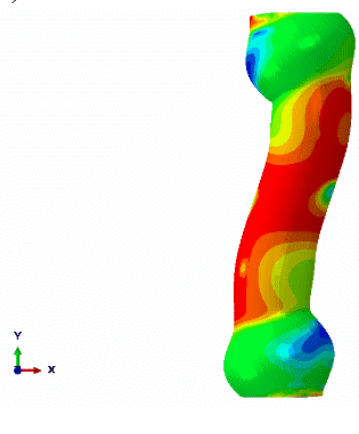

(a)

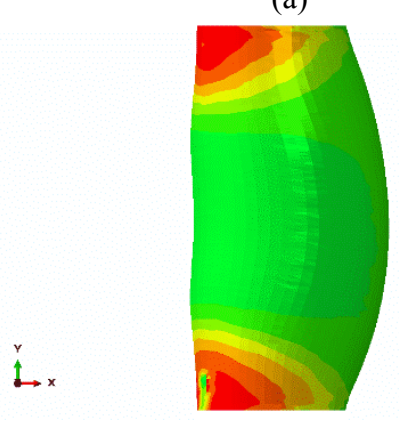

(c)

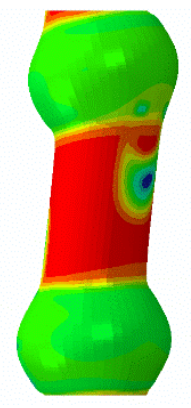

(b)

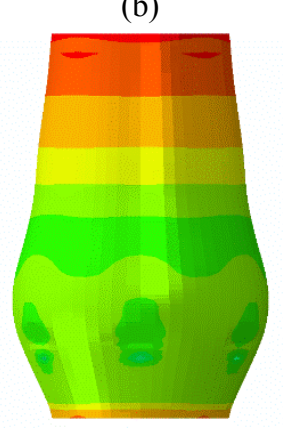

(d)

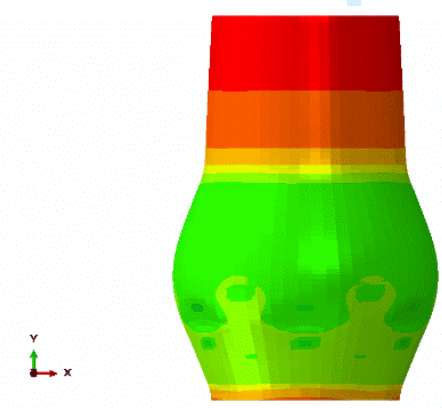

(e)

\subsection{Temperature field distribution}

In the simulation of hot upsetting process, the main factors affecting the temperature are deformation heat, heat transfer between die and cylindrical billet and surface heat dissipation. Fig. 10a shows the temperature distribution at $900^{\circ} \mathrm{C}$, take three points A (at the bottom surface), B (at the outer surface) and $\mathrm{C}$ (at the center of the cylindrical billet), and observe their temperature changes.

Fig. 10. Temperature characteristics during hot upsetting. (a) temperature field. (b) variety of temperature at different positions. 


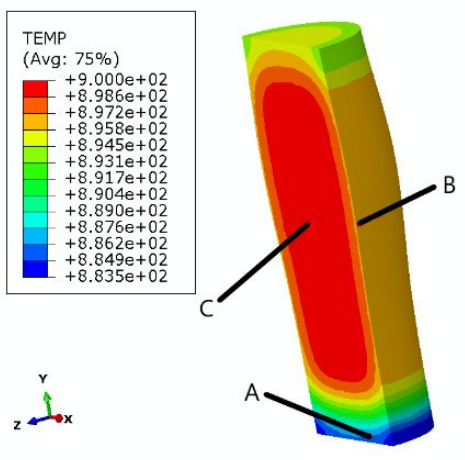

(a)

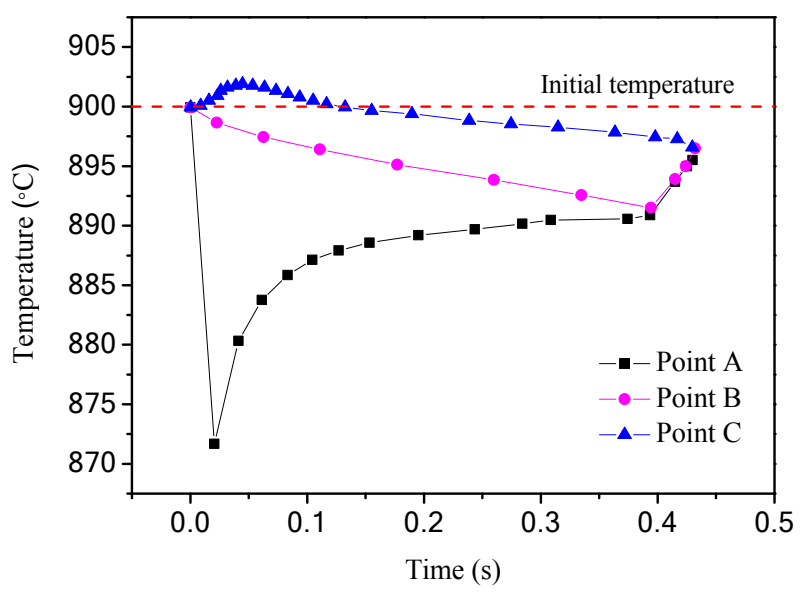

(b)

As shown in the Fig. 10b, at point $\mathrm{C}$, a small temperature rise occurs while maintaining a relatively high temperature. This is due to during the actual upsetting process, cylindrical billet can be divided into three deformation areas according to the degree of deformation, as shown in Fig. 11, "I " represents the difficult-deformation area, "II" represents the easy-deformation area, and "II" represents the freedeformation area. To be sure, the easy-deformation area will generate a lot of deformation heat, this is the reason for the temperature increases at point $\mathrm{C}$. In addition, the temperature of point $\mathrm{B}$ occurs a light decrease, which is due to the convective heat exchange between the surface and the air during the upsetting process. However, the film coefficient value is too small to the temperature drops lightly. Then, when the surface encounters the die cavity, the temperature rises again. For point $\mathrm{A}$, the temperature rapidly drops and then slowly rises. The large temperature difference between the bottom surface of billet and the surface of bottom die is the reason for the sharp drop of temperature at point $\mathrm{C}$, and the subsequent rise is due to the heat generated by deformation. Finally, the temperature of each part of the cylindrical billet tends to be stable.

Fig. 11. Upsetting deformation zone.

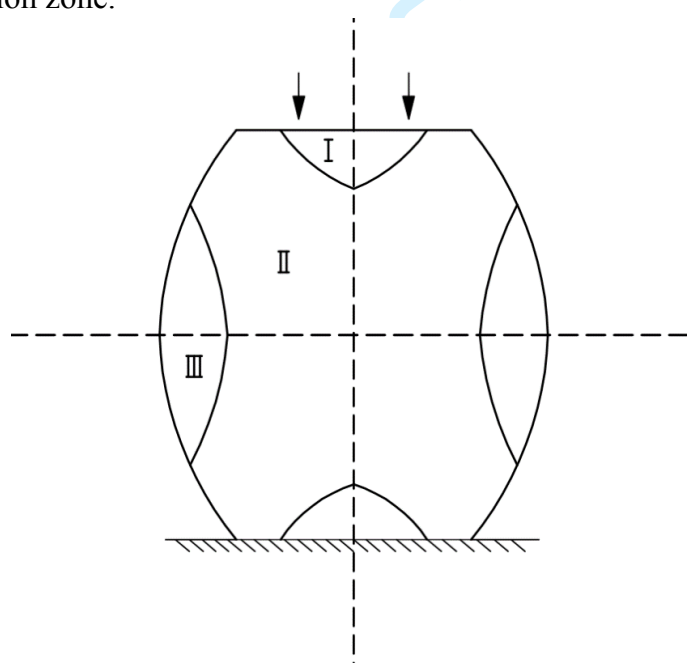

\subsection{Equivalent strain distribution}

Fig. 12a shows the equivalent strain distribution of the self-locking nut, it can be seen that the strain value of the head is the highest, followed by the center, and the lowest at the bottom. Then, take three points on the nut and observe the change of the equivalent plastic strain. As shown in Fig. 12b, we can find that during the continuous pressing process of the upper die, the equivalent plastic strain of each part of the cylindrical billet increases, and the strain in the center is the largest. When the analysis step time is about $0.38 \mathrm{~s}$, the cylindrical billet starts to contact with the inner wall of bottom die cavity, and then the cylindrical billet was seriously extruded by the upper die and bottom die cavity at the same time, so the equivalent plastic strain increases sharply. In addition, in order to reflect the uniformity of equivalent 
strain, we introduce the deformation uniformity coefficient $\zeta$, it can be obtained as (Li et al. 2020):

$$
\zeta=\frac{\varepsilon_{\max }-\varepsilon_{\min }}{\varepsilon_{\text {ave }}}
$$

where, $\varepsilon_{\max }$ is the maximum value of equivalent strain, $\varepsilon_{\min }$ the minimum value of equivalent strain, and $\varepsilon_{\text {ave }}$ is the average value of equivalent strain. The smaller the deformation uniformity coefficient $\zeta$, the more uniform the deformation ( $\mathrm{Li}$ et al. 2020). Based on this, the variation of deformation uniformity coefficient under different temperatures is shown in the Fig. 13. It can be seen that the higher the temperature, the more uniform the deformation of the billet.

Fig. 12. Equivalent strain distribution during hot upsetting. (a) equivalent strain field. (b) curves of nodal strain.

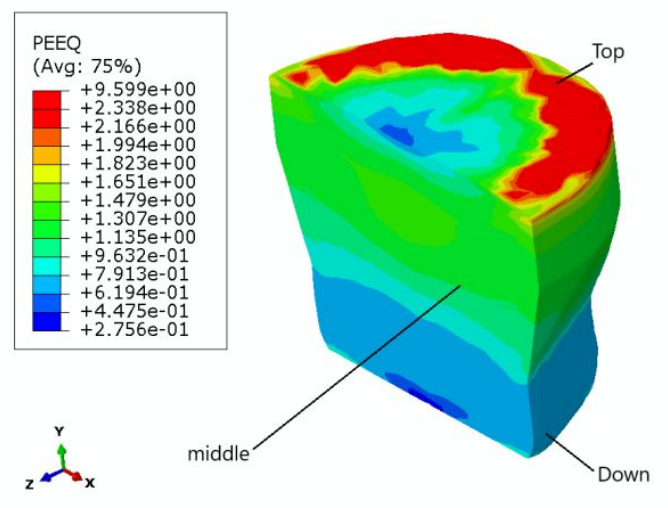

(a)

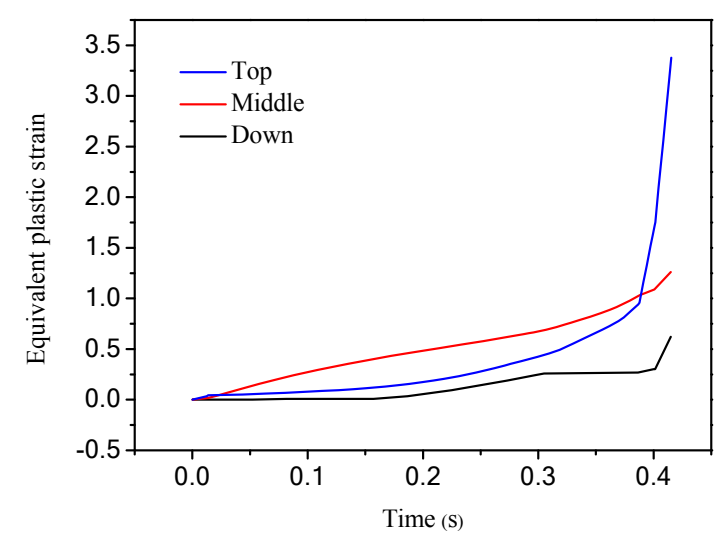

(b)

Fig. 13. Deformation uniformity at different temperatures

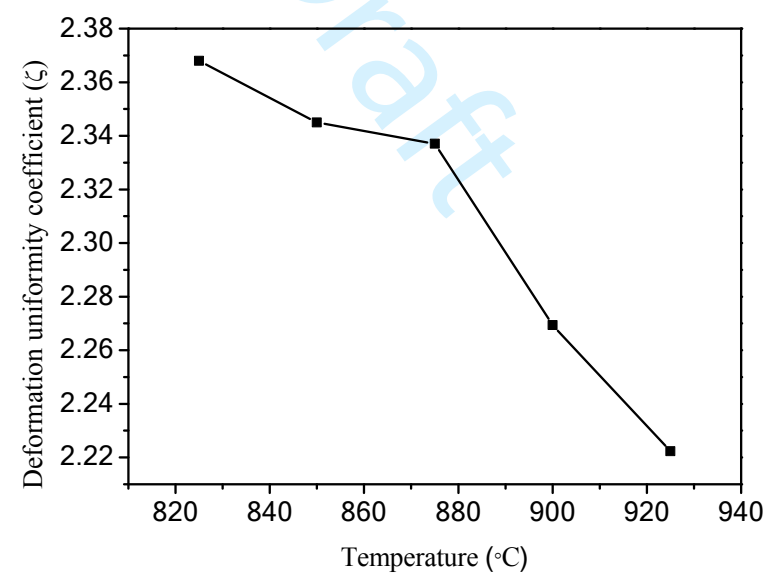

\subsection{Formability}

As shown in Fig. 14, the appearance of nut forming obtained from simulation and experiment was compared. It is obvious that the results of simulation are similar to the corresponding results of experiment, which validates the accuracy of the finite element model. Then, in order to explore the influence of temperature and deformation velocity on formability, the volume of hexagonal prism (the red wireframe of Fig. 15) was calculated at different temperatures and different velocities. The influence of initial temperature and velocity of the upper die on the volume of hexagonal prism is shown in Fig. 16. In terms of temperature, with the temperature increases, the cylindrical billet tends to be close to the die, the forming quality of TC4 nut performs better. Therefore, the forming quality is preferable at $900^{\circ} \mathrm{C}$ and $925^{\circ} \mathrm{C}$. When the temperature exceeds $900^{\circ} \mathrm{C}$, the increase of filling volume tends to be stable. And in terms of deformation velocity, the increase of the velocity of the upper die has a slight negative effect on the forming quality: the higher the velocity of the upper die, the smaller the filling volume. Based on the above discussion, it can be concluded that in the process of nut hot upsetting, it is beneficial to increase the upsetting temperature and reduce the die velocity to the formability of the nut. 
Fig. 14. Complete forming appearance. (a) simulated results. (b) experimental results (Wang et al. 2015).
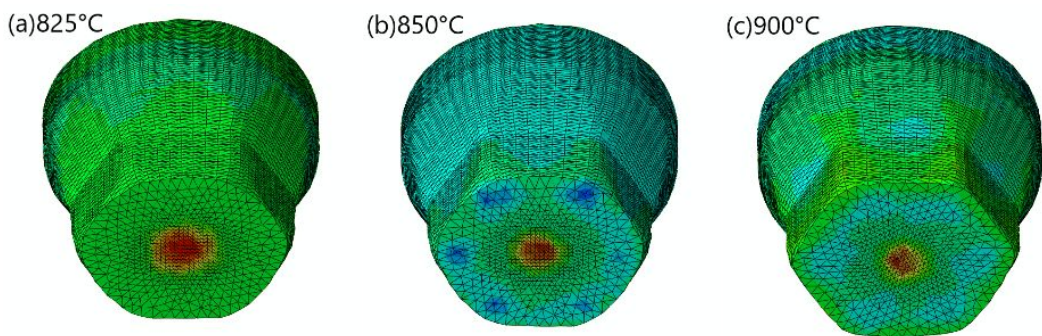

(d) $925^{\circ} \mathrm{C}$

(a)
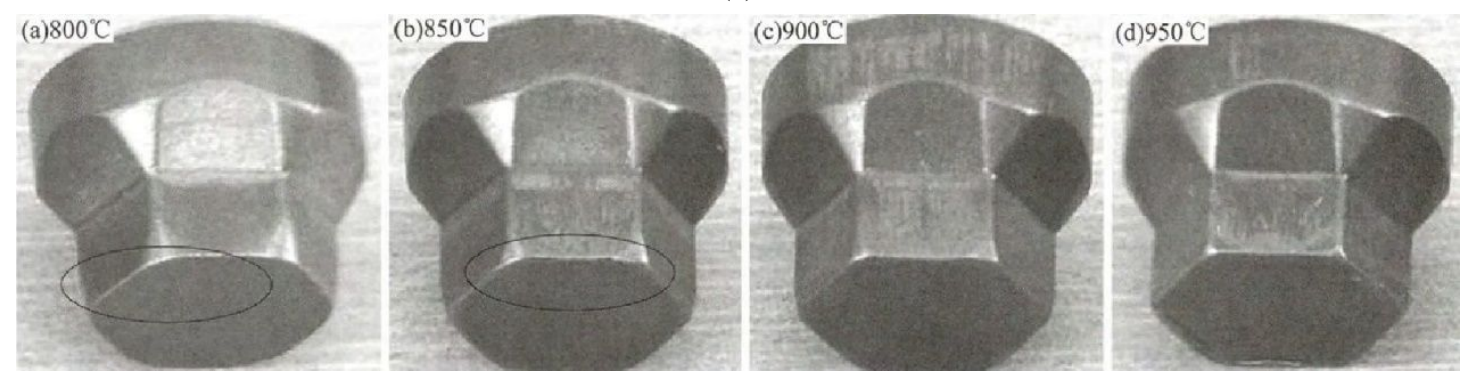

(b)

Fig. 15. Unfilled hexagon part.

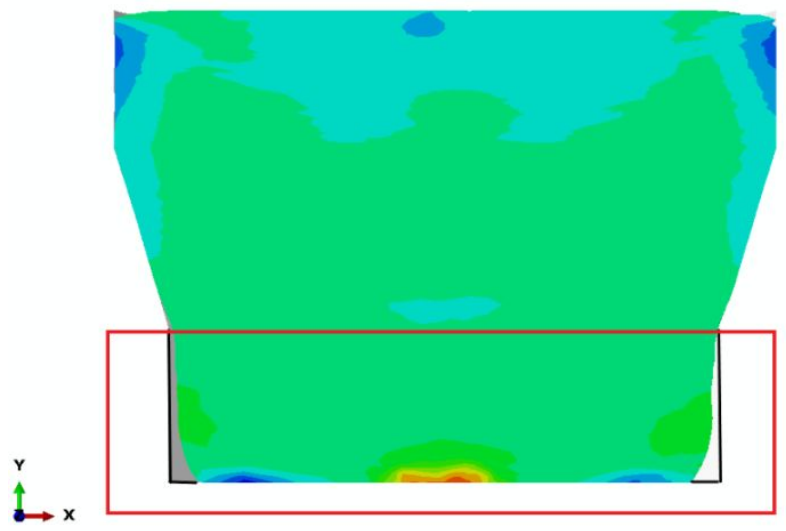

Fig. 16. Volume of hexagonal prism at different temperatures and different velocities.

Deformation velocity $(\mathrm{mm} / \mathrm{s})$

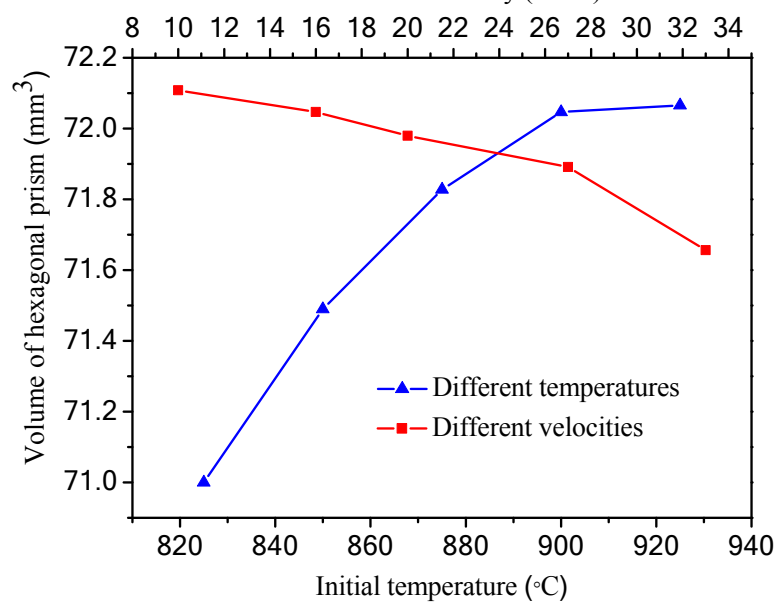

\section{Conclusion}

1) The size of the cylindrical billet will have a great influence on the forming stability of the hot 
forging. When the length-diameter ratio of the cylindrical billet is less than 3.27 , the forming tends to be stable.

2) Due to the influences of surface heat dissipation, heat conduction and deformation heat, the temperature distribution of the billet is not uniform, and the highest and lowest temperatures appear in the center and bottom of the nut, respectively.

3) According to the distribution of equivalent strain of nut, strain value of the head is the highest, followed by the center, and the lowest at the bottom. And the deformation uniformity is affected by temperature. The higher the temperature, the more uniform the deformation of the billet.

4) The formability is affected by initial temperature and velocity of the upper die in different degrees. Both higher temperature and lower velocity of the die are beneficial to the forming of the nut.

\section{Acknowledgements}

The authors gratefully acknowledge the financial support by the Key Research and Development Project in Shandong Province (2019JZZY010122) and Natural Science Foundation of Shandong Province (ZR2019MEE074).

\section{References}

Abbasi-Bani, A., Zarei-Hanzaki, A., Pishbin, M.H. and Haghdadi, N. 2014. A comparative study on the capability of Johnson-Cook and Arrhenius-type constitutive equations to describe the flow behavior of Mg-6Al-1Zn alloy. Mech. Mater. 71: 52-61. doi:10.1016/j.mechmat.2013.12.001.

Alimov, A., Sizova, I., Biba, N. and Bambach, M. 2020. Prediction of mechanical properties of Ti-6Al4V forgings based on simulation of microstructure evolution. Procedia Manufacturing. 47: 14681475. doi:10.1016/j.promfg.2020.04.326.

Cai, J., Li, F.G., Liu, T.Y., Chen, B. and He, M. 2011. Constitutive equations for elevated temperature flow stress of Ti-6Al-4V alloy considering the effect of strain. Mater. Design. 32(3): 1144-1151. doi:10.1016/j.matdes.2010.11.004.

Cheng, M.W., Liu, F.L., Li, W.Q. and Wang, L.D. 2020. Study on microstructure evolution rule of multistation upsetting for stainless steel high-lock nut. Hot Working Technology. 49(5): 103-107. doi: 10.14158/j.cnki.1001-3814.20183526.

Editorial board of China Aviation Materials Handbook. 2002. China aeronautical materials handbook. 4: 104-132.

Feng, W., Mao, L. and Zhou, M.J. 2018. Effect of relief-hole diameter on microstructure evolution of 20CrMnTiH steel during hot upsetting. Procedia Manuf. 15: 388-395. doi: 10.1016/j.promfg.2018.07.234.

Huang, K., Liu, J., Tao, Y.D., Ding, R.H. and Tian, W.R. 2019. Establishment of Arrhenius constitutive equation for flow mechanics andanalysis of recrystallization nucleation mechanism of GH4720Li alloy. Trans. Mater. Heat. Treat. 40(1): 141-148. doi:10.13289/j.issn.1009-6264.2018-0288.

Hsia, S.Y. and Chou, Y.T. 2016. Tooling design improvement of multistage cold forging of specialty shaped nuts using CAE and 3D printing. Trans. Can. Soc. Mech. Eng. 44(4): 501-510. doi:10.1139/tcsme-2016-0038.

Jiang, Y.Q., Lin, Y.C., Wang, G.Q., Pang, G.D., Chen, M.S. and Huang, Z.C. 2021. Microstructure evolution and a unified constitutive model for a Ti-55511 alloy deformed in $\beta$ region. J. Alloys Compd. 870: 159534. doi:10.1016/j.jallcom.2021.159534.

Jiang, Y.Q., Lin, Y.C., Jiang, X.Y., He, D.G., Zhang, X.Y. and Kotkunde, N. 2020. Hot tensile properties, microstructure evolution and fracture mechanisms of Ti-6Al-4V alloy with initial coarse equiaxed phases. Mater. Charact. 163: 110272. doi:10.1016/j.matchar.2020.110272.

Kazuhiro, M., Takuro, E., Yong-Bum, C. and Gen, S. 2010. Alloy design of Ti alloys using ubiquitous alloying elements and characteristics of their levitation-melted alloys. Mater. Trans. 51(4): 740-748. doi:10.2320/matertrans.F-M2010801.

Kukhar, V. V., Balalayeva, E.Y., Korenko, M.G., Prysiazhnyi, A.H. and Anishchenko, O.S. 2021. Fem simulation of C45 steel and Cu-ETP billet shaping at hot upsetting between convex conical dies. IOP Conference Series Materials Science and Engineering, 1018: 012012. doi:10.1088/1757- 
899X/1018/1/012012.

Li, Y.Z., Xie, Y.M. and Ji, L.B. 2020. Effect of round corner radius of twist extrusion die channel on plastic deformation of copper alloy. J. Plast. Eng. 27(11): 97-102. doi: 10.3969/j.issn.1007-2012. 2020.11.015.

Lin, Y.C., Jiang, X.Y., Shuai, C.J., Zhao, C.Y., He, D.G., Chen, M.S. and Chen, C. 2018. Effects of initial microstructures on hot tensile deformation behaviors and fracture characteristics of Ti-6Al4V alloy. Mat. Sci. Eng. A. 711:293-302. doi:10.1016/j.msea.2017.11.044.

Liu, H.J., Xue, Y., Zhang, Z.M., Ren, L.Y., Wu, Y.J., Xu, J. and Yan, J.P. 2020. Effect of multi-pass hot deformation on flow stress and microstructure of Ti-6Al-4V titanium alloy prepared by hot isostatic pressing. Procedia Engineering. 50: 652-657. doi:10.1016/j.promfg.2020.08.117.

Luo, S.Y., Yao, J.N., Zou, G.M., Li, J., Jiang, J. and Yu, F.P. 2020. Transformation characteristics of temperature and phases within Ti-6Al-4V aeroengine drum in hot forging and air cooling procedures. J. Mater. Res. Technol. 9(4): 8235-8244. doi:10.1016/j.jmrt.2020.05.096.

Maarefdousta, M. and Hosseyni, M. 2011. Simulation and analysis of finite volume of hot forging process of nut. AIP Conf. Proc. 1383: 581-587. doi:10.1063/1.3623660.

Mohanraj, R. and Elangovan, S. 2020. Incremental sheet metal forming of Ti-6Al-4V alloy for aerospace application. Trans. Can. Soc. Mech. Eng. 44(1): 56-64. doi:10.1139/tcsme-2018-0276.

Paul M, S., Joseba, M., Qi, C., Hossein, B., Peter D, H. and Bernard, R. 2019. A microstructural based constitutive approach for simulating hot deformation of Ti6Al4V alloy in the $\alpha+\beta$ phase region. Mat. Sci. Eng. A. 748: 30-37. doi:10.1016/j.msea.2019.01.081.

Seetharam, R., Kanmani Subbu, S. and Davidson, M.J. 2017. Influence of temperature on the workability and hardness of sintered $\mathrm{Al}-4 \% \mathrm{~B} 4 \mathrm{C}$ in upsetting test. Procedia Engineering. 173: 910-917. doi: 10.1016/j.proeng.2016.12.140.

Shen, Q.Y., Shan, L.L., Zhang, X.B., Wang, Y.F., Liu, B.L. and Xin, X.R. 2014. Research of precision warm-forming by floating-die for titanium alloy nut. Technology \& Forging Stamping. 39(2): 7478. doi:10.13330/j.issn.1000-3940.2014.02.015.

Shi, X.Y., Fu, B.Q., Wang, W.S., Tang, X.D. and Chan, X.M. 2010. Effect of forging temperature on mechanical property and microstructure of TC4-DT titanium. Chin. J. Nonferrous. Met. 20(1): 7982. doi:10.19476/j.ysxb.1004.0609.2010.s1.019.

Wang, D.G., Wu, Y.C., Jiao, M.H., Yu, J.W. and Xie, T. 2008. Finite element simulation of influence of different compacting processes on powder metallurgic products properties. Chin. J. Mech. Eng-en. 44(1): 205-211. doi:10.3321/j.issn:0577-6686.2008.01.036.

Wang, K.H., Mateusz, K., Chang, S.P., Qu, B., Liu, J., Denis J, P., Wang, L.L. and Liu, G. 2020. Enhanced formability and forming efficiency for two-phase titanium alloys by Fast light Alloys Stamping Technology (FAST). Mater. Design. 194:1-12. doi:10.1016/j.matdes.2020.108948.

Wang, L.D., Liu, F.L., Zhao, Q.Y. and Liang, F.S. 2015. Influence of hot upsetting temperature on forming property of titanium alloy self-locking nut with complex surface. Hot Working Technology. 44(13): 150-156. doi:10.14158/j.cnki.1001-3814.2015.13.045.

Werner, W. and Werner, S. 2019. Microstructure and texture development in oxide-dispersion strengthened silver rods processed by hot-extrusion. Materialia. 5. doi:10.1016/j.mtla.2018.11.024.

Xiao, Y.W., Lin, Y.C., Jiang, Y.Q., Zhang, X.Y., Pang, G.D., Wang, D. and Zhou, K.C. 2020. A dislocation density-based model and processing maps of Ti-55511 alloy with bimodal microstructures during hot compression in $\alpha+\beta$ region. Mat. Sci. Eng. A. 790:139692. doi:10.1016/j.msea.2020.139692.

Yang, M.J., Xie, Y.J., Yin, J.J., Han, L.L. and Zhou, X.Y. 2016. Experimental study on the relationship between young's modulus and temperature of metal tube. Physical Experiment of College. 29(2): 52-55. doi:10.14139/j.cnki.cn22-1228.2016.002.014.

Yeganefar, A., Niknam, S.A. and Songmene, V. 2020. Machinability study of aircraft series aluminium alloys 7075-T6 and 7050-T7451. Trans. Can. Soc. Mech. Eng. 44: 427-439. doi:10.1139/tcsme2019-0215.

Zhang, J.S., Liu, H.J., Xu, K.H., Zhang, Z.M., Wang, Q. and Xue, Y. 2021. Effect of multi-pass 
deformation on microstructure and flow behavior of Ti-6Al-4V alloy fabricated through hot isostatic pressing. Mater. Res. Express. 8: 016519. doi:10.1088/2053-1591/abd8a0.

Zhang, L.J., Chang, H. and Xue, X.Y. 2013. Hot process of titanium and titanium alloy. Hot Working Technology. 42(2): 82-87. doi:10.14158/j.cnki.1001-3814.2013.02.066.

Zhao, D., Yang, Y.S., Yao, Y.W., Yang, L., Wang, K. and Kang, J.M. 2015. Study on compressive deformation behavior of TC4 titanium alloy. Southern Metals. (6): 18-20. doi:10.3969/j.issn.10099700.2015.06.004 